\title{
An Analysis of the Implementation Barriers to Quality Standards in Higher Education of Kingdom of Saudi Arabia
}

\author{
Dr. Fahd Mohammad Albejaidi \\ Assistant Professor \\ College of Public Health and Health Informatics, Al-Bukayriyah, Qassim University, Kingdom of Saudi Arabia \\ Dr. Ghulam Muhammad Kundi \\ Professor of Management Sciences \\ Department of Public Administration, Gomal University, DIKhan, Pakistan
}

\begin{abstract}
Higher education system of the country plays a very important role in education of the nation. This research study was designed and aimed to investigate into the implementation barriers to quality standards in the higher education of the Kingdom of Saudi Arabia. The study was exploratory and qualitative in its essence through which extensive review of the literature was done. A computer based software ATLAS.ti was used for data analysis. Research model was developed to know the relationship and impact of dependent and independent variables i.e. Governmental Planning, Organizational and Human Resources on the implementation of the Quality Standards in higher education of Saudi Arabia. The study found that government, organizational and human factors significantly affect the implementation of quality standards in higher education of Saudi Arabia, therefore, government is required to regularly monitor and assess the quality standards execution round the years in order to streamline the governmental planning, organizational dimensions to support the effective implementation of quality standards in higher education.
\end{abstract}

Keywords: Higher Education, Quality Indicators, Quality Assurance, Quality Standards, Implementation Barriers, Government, Organization and Human Resources.

DOI: $10.7176 / \mathrm{JEP} / 10-28-01$

Publication date:October $31^{\text {st }} 2019$

\section{Introduction}

Education enlighten the society and leads the nations towards modernization and advancement, which pave way for the socio economic development and prosperity Abdullah (2010). Recognizing this fact, the developing countries are focusing on this critical sector of the economy by allocating more funds and resources. Every nation passes through good and bad experiences, however, those who achieved the goals of higher literacy and education are now leading the world in agriculture, industry, technology and services sectors. The advancement and development of any of the country is thus not only dependent on education but on the higher education in the country. Today round the globe, experts' emphasis not merely on provision of education but quality education (Morcol (2007). Quality is a yardstick the measure the excellence of the education system (Joshi, 2014). Thus, higher education performs a pivotal role in the socio and economic uplift and development of any society. Particularly, the universities, since their inceptions from centuries, have been playing instrumental and significant role in educating the professionals, business men, social, religious and scholars in the society, who served their nations by enriching their norms and values and to develop their resources, as Heather (2013) concludes.

\section{Literature Review}

\subsection{Higher Education}

The significance of education is well understood around the globe and now it is one of the priority areas of political agenda in almost all the developing countries. Kingdom of Saudi Arabia has paid attention to this sector in very beginning. Saudi Arabia, since its existence trying its best to reform the higher education system to cater its needs and requirements thus spending a great chunk of its resources i.e. more than $4 \%$ of GDP on the development and promotion of higher education throughout the kingdom as recommended by UNESCO for all developing countries (UNDP, 2002). It has been found that with the emergence of the concept of globalization and knowledge based economies, the role of higher education has turn into more vivacious and crucial in general, and in particularly the quality of education has been considered now an imperative for the national development. However, the big issue and challenge with transitional societies like, Saudi Arabia is that it paid attention to the quality in higher education very late. The World Bank (2000) in its report mentioned that "without quality and better higher education, it will be hard for developing countries including Saudi Arabia to get benefits from the emerging global knowledgebased economy. 


\subsection{What is Quality Education?}

According to the Education Department of the United States of America (2002), quality of education implies the attainment of the national educational objectives, which include the social excellence, national excellence and academic excellence. Chande (2006), contends that satisfaction of the user, use of the entry qualification, retention of the students, learning and teaching output, research, graduate employment, and change in attitude and behavior of the students are some of the important statistical and non-statistical indicators of quality education which focus on the objective measurement that how a higher education institution is performing?

The indicators of quality have been divided into three groups' i.e. inputs, which consists of different measures for example, the financial, physical and manpower measures that are linked with the resources which are meant for the students at each educational level (Olaniyan \& Okemakinde, 2008). Likewise, the financial measures are also directed towards per student educational cost. Similarly, the physical measures include the age, condition, and comprehensiveness of the laboratories, classrooms, and libraries etc. (Gorga, 2011) On other hand, the manpower measures focus on the number of different types of personnel which are expressed in terms of different ratios with regard to the number of the student at each level, it also includes the background information regarding the educational qualifications, experience, attitude, behavior, knowledge and core competencies Lundin (2007). The educational outputs, on the other side, talk about the consequences of the educational process which are reflected in measures, for example, knowledge, skills and values that are attained by the students, moreover, the educational processes simply include curriculum development to the final assessment e.g. it consists of the admission, teaching and learning. It is difficult to measure these quality indicators, however, Durlak \& DuPre (2008) have presented five approaches to measure quality in higher education, including, in terms of the exceptional (higher standards), consistency (i.e. the zero defects with getting it right from the first time), as a fitness for purpose (meeting the stated purposes), and as a value for the money and last but not least as transformative (change of the participant).

However, Heather (2013) has suggested that it is necessary to define the quality before initiating any mechanisms. Yet the biggest issue in quality management and in assessing the quality is that how to maintain an equilibrium and balance between the internal and external evaluators. Currently with reference to quality in higher education, two quality standards i.e. the ISO 9000 series of auditable quality standards and second, the evolving Global Alliance for Transnational Education (GATE) and popular and in practice. A variety of the criteria are available for external review, Lundin (2007) share similar views. He further extends that if the quality standards are followed by the higher education institutions, the universities of the developing countries could then get space and recognition in the international rankings. Durlak \& DuPre (2008) explains that quality of the education through quality assurance systems increases the confidence of the students on the institution standard will be maintained. Likewise, Beso et al. (2008) notes that quality assurance in higher education institutions is a preplanned consists of deliberate activities which are initiated and that are followed with the determined tenacity of maintaining and improving the quality of learning of the members in higher education institutions.

Above all, Heather (2013) comprehensively defined it as a "mechanism and procedure that is designed to reassure different participants of the higher education, that this institution give a high priority to the implementation of such policies which are designed for the maintenance and enhancement of the effectiveness of the institution. Thus, it is reported by experts, that it is the mix of several principles, such as setting the quality objectives, planning the activities to achieve these objectives along with the philosophy to promote the motivation and commitment. Durlak \& DuPre (2008) criticize these views and argues that the overall quality of the university depends on all the aspects of the functions which are performed by the university.

The two main approaches of quality assurance in higher education are the external and internal approaches. The former states that an internal committees among the faculty of the institution could be kept on trajectory from time and again by the guidance of the external review committees (Beso et al., 2008), which could include members from a group of universities and their faculties (Dobbins \& Knill, 2009). However, Lundin (2007) suggest that the first stage of external review "must be a document reporting the self- evaluation, yet according to him quality assurance could be achieved through an individual program in a university through internal review.

Similarly, on other side, European Association for Quality Assurance in Higher Education (2009) observed that quality assurance is first and critical step for any institutions to excel in the age of competition in order to satisfy their customers, (Gorga, 2011), however, he further adds that this will have positive and significant effect on the involvement, interest and effectiveness of the teaching. And finally, it is also imperative to make an outcome assessment, which implies the monitoring, assessment and evaluation of the institution as well as of the students. It is evident that these three cited components of quality assurance systems must focus on the integrated approach to the quality of teaching and quality of programs in an educational institution.

\subsection{Quality in Higher Education}

The quality in higher education is a dynamic and multidimensional concept that encompass all the relevant activities and functions which are part of the academics in a university. It has been suggested that any quality mechanism initiated by universities thus must consider the quality of infrastructure, teachers, students, student 
support services, curricula, assessment methods and the learning resources (Agranoff \& Yidiz, 2007). The major indicators of quality education includes the quality of the faculty, development of the faculty, instructional development, organizational development, teachers training programs i.e. pre-service, in-service training, seminars, workshops, and conferences etc. (Dobbins \& Knill, 2009) is of the opinion that the quality of the management and governance of the university is a coherent and coordinated efforts which have interaction with its environment, as it is extremely difficult rather impossible for a university to operate as isolated enclaves. Thus, in dynamic world, the rapid proliferation of knowledge could be useful to management, as it demands a higher quality of administrators (Churchman, 2006). With this background in mind, it has been noted by several studies that quality of higher education is strictly linked and dependent upon the systemic evaluation and regulations. Which necessitates promotion and inculcation an evaluation culture in the institution.

\subsection{Higher Education in Kingdom of Saudi Arabia}

The nucleus of higher education in Saudi Arabia traced back to the approval of King Abdul Aziz who send 14 students in different fields of specialization to Egypt in 1927 due to the urgent need of the kingdom. However, the actual beginning of higher education in the Kingdom of Saudi Arabia happened sixty years ago; the first unit being the College of Islamic Law in Makkah was established in 1949, wherefrom the journey started and other colleges and universities continued to be founded, until our prosperous time, in which we are witnessing the great higher education renaissance, manifested in the establishment of higher education institutions in all provinces and districts of the Kingdom. The history of higher education in Saudi Arabia could be divided into three stages i.e. Foundation Stage (1949 to1960), during this is the stage in which the first blocks in the higher education edifice were laid down. During the second stage (1961-1980) establishment of universities and colleges in all the provinces took place consisted of 58 colleges of various disciplines. The third stage was named a comprehensiveness stage (19812009). This stage is one in which the Saudi government was evidently intent on spreading the institutions of higher education in the various provinces and districts of Saudi Arabia, the latter being over 77 in number.

The Ministry of Higher Education has been endeavoring to guarantee high standards of quality in higher education through programs and channels that emphasize the human factor and research, which together constitute the major artery of higher education. The Ministry has launched the program of international leadership in Saudi universities as a project of augmenting the quality of higher education institutions. Through this program, the Ministry hopes to achieve a qualitative leap in Saudi universities and to support them in order to accomplish international leadership in the various areas and specializations, particularly those that are well-suited to the Kingdom's mission and aspirations in this field. It is hoped that this program will give additional support to Saudi universities and contribute to the success of their programs. It is also hoped that an increase will be realized in research projects and specialized studies, leading to publications in outstanding international publication vehicles, to the undertaking of joint research, and to partnerships with various, reputed academic and research institutions all over the world. The program aspires to achieve a greater exchange of faculty members and researchers, and to benefit from the experience of these institutions in higher education programs through visiting student programs and scholarships. The international leadership program is expected to lead to advanced levels of academic accreditation for several Saudi universities.

The National Commission for Assessment and Academic Accreditation was established in 2004 under the Royal decree on 9/2/AH 1424, corresponding to 11/4/2003. The commission was given the responsibility for academic accreditation and quality assurance in the post-secondary institutions of higher education. The Commission started its functioning under the supervision of the Higher Education Council. However, this relationship was changed under the Royal directives on 25/11/AH 1424 (17/1/2004), and ow the commission was placed under the supervision of the Supreme Council for Education. The aim of the commissions were formulate the rules, standards and conditions governing assessment and academic accreditation, as well as the criteria which guarantee their application in the various postsecondary level academic institutions besides general accreditation of new universities or other similar institutions, moreover it was responsible for the periodic review and evaluation of the academic performance of existing universities or other similar institutions along with academic accreditation of their departments and instructional programs. Likewise, the Commission has been empowered to establish permanent academic committees along with the other permanent or temporary adjunct committees. The commission also publish the data and information regarding accreditation for the purpose of general awareness, media use, or academic research, as well as making such information available to individuals (Report Saudi HE, 2012). The report further elaborates that the commission has achieved a number scientific and professional objectives like, membership with international organizations i.e. International Network for Quality Assurance Agencies in Higher Education (INQAAHE), system of assessment and academic accreditation, national framework for qualifications, guide to quality and academic assessment system and project for the developmental assessment of the system of assessment and quality assurance. It is with the efforts of this commission that, King Saud University and King Fahd University of Petroleum and Minerals have been ranked among the best 300 universities worldwide in the 2010 QS World University Rankings. The US News and World Report King Saud University 
ranked 222nd and King Fahad University of Petroleum and Minerals $255^{\text {th }}$ in the world according to the US News and World Report 2011.

2.5 Barriers to implementation of Quality Standards in the Higher Education of Kingdom of Saudi Arabia One cannot disassociate the issue of quality from the quest for excellence and its implementation. The implementation of quality standards in the local institutions with a global perspective is a serious issue in Saudi higher education system. The need to develop a culture of proper implementation and acceptance of the concept of quality is essential for the success of a higher education system.

The main issue that impede the implementation of quality standards in HEIs include both the internal as well as external factors which are ranging from governance and academics, accreditation, organizational, human, technological, socio-economic, cultural, political and psycho-social constraints to lack required human and material capital, development of feudal mind set and resistance to change (Gorga, 2011). If a comprehensive and multi-level mechanism of accreditation is developed then one can expect the provision of quality education.

According to higher education commission, accreditation needs mostly happen at the department as well as at the program level besides the institutional level. The problems being faced by developing countries including Saudi Arabia which impede the implementation of quality standards in higher education system include the challenges in the governance and academics, accreditation, organizational, human, technological, socio-economic, cultural, political and psycho-social constraints, the lack of the required human and material resources, development of feudal mind set and resistance to change (Raines, 2007).

However, above all the key factors with regard to Saudi higher education system are the quality of faculty, curriculum standards, technological arrangement, research milieu, accreditation system and the administrative policies and procedures implemented in the institutions of higher learning (Abdullah, 2010). Different issues that also hinder the implementation of quality standards in higher education of the Saudi Arabia as identified include the lack of effective governance and management structures and practices, lack of the optimum use of available resources, defects in planning, poor recruitment practices and inadequate development of faculty and staff, derisory support for research, strong cynicism about the realization of reforms, however, to sum up, it may be concluded that there are three factors that thwart the implementation of quality standards in the Saudi higher education:

\subsubsection{Governmental Barriers (Planning)}

Governmental Planning play leading role in success of any sector including higher education through up to date higher education policy especially the government urge, will and support for accreditation and standardization policy besides inappropriate funding along with interference in the internal administrative and academic affairs of the higher education system either through appointment, transfers etc. (Westerheijden et al., 2010). Provision of physical, technical and legal infrastructure to executive the standards of quality is also responsibility of the government (Harvey \& Williams (2010).

\subsubsection{Organizational Barriers}

The organizational barriers are also grouped into the set of sub-systems, these sub systems include the mission, size, structures, culture, resources, admissions, validations and management, which are interdependent, intercoordinated and interrelated, and regularly interacting with one another inter alia the local, national, regional and international environment (Churchman, 2006). The inability or lack of good governance is a bottle neck to implementations of quality standards. Red tapism, cumbersome procedures, vast autonomy and unlimited powers also hinders the implementation of quality standards (Gorga, 2011).

The organizational factors including lack of good governance, conventional structure, and the culture of buck passing besides keep on pending work for next day beside lack of top management support is also a critical and significant factor that influence and cause failure in smooth implementation of any of the system especially quality standards as it may take power from one and empower the other (Churchman, 2006). Organizational politics, and maneuvering over the resources let down the pace of implementation slower (Westerheijden et al., 2010).

\subsubsection{Human Resource Barriers}

The human factors include the requisite qualification, experience, competence, aptitude and inclination besides sincerity and devotion to work among all the work force including academic staff, administrative staff and ministerial and technical staff. Change management and resistance to overcome the resistance to change (Onsman, 2010). Appointment, promotion and awards must be based on meritocracy. Thus, quality of the higher education is dependent upon the quality of the teachers i.e. acceptable social status; the drive to reduce inequalities such as ender inequality; the concern to manage the affairs of teachers according to merit criteria, and provision of inservice training; instituting the incentives structures to inspire the researchers to employ their research skills and to work in multidisciplinary teams on the approved projects (Simplicio, 2008).

Moreover, the quality of the curricula and students also have significant role which may not be play down. Likewise, Westerheijden et al. (2010) asserts that quality of infrastructure and quality of management of the institution which being a coherent whole, interacting with its environment, thus can result into opportunities as well as threats. Sharing same views, however, Churchman (2006) further adds that inculcating the culture of 
evaluation which involves developing the culture of autonomy, responsibility and accountability is also a precondition for the successful implementation of quality standards.

Lack of top management Ssupport, the inability to utilize optimum resources besides, centralization and lack of participation of the stakeholders in formulation of policies, decision making and results into resistance to change, hence impede the execution process (Eqbal et al., 2015). Furthermore, the lack internationalization and further contextualization, in designing the quality standard programs for teaching and its application according to standards is also important issue that needs attention of the researchers (Agranoff \& Yidiz (2007).

In general, the standards have been adopted without customizing them in accordance with the local conditions is one of the major barriers towards effective implementation of the quality standards in Saudi higher education system. Likewise, lack of coordination and cooperation also play important role in the success or otherwise failure of the implementation of quality standards in different field including higher education system. A universal vision of higher education hint at multiple forms of coordination and co-operation involving all the institutions in developing and implementing the quality standards in higher education system, the objective is to work towards sustainable human development (UNESCO, 1996).

This lack of coordination and cooperation might be due to varying perceptions, miscommunication etc. however, it is argued by several researchers that to effectively put into place the quality standards in higher education institutions, there is dire need to strengthen the bod of relationship, confidence and trust between and among the central government, higher education and national quality accreditation commission (Churchman, 2006).

\section{Research Methods}

Literature review was carried on the existing research. A computer based software ATLAS.ti was used for data analysis. The main variables of the study and sentences were fed into ATLAS.ti. Furthermore, coding, extraction of quotes and memos were created.

Researcher recommends the examination, categorization, tabulation and recombination for qualitative data analyses. In this research the researcher has used hermeneutics (James, 1992), discourse (Max, 1990) and heuristic (Moustakas, 1990) analyses to find the fact.

\subsection{Theoretical Framework of the Study}

The figure-1 given below explain the relationship and impact of dependent and independent variables of the study. Independent variables includes the Governmental, Organizational and Human Resources factors while implementation of the Quality Standards in higher education of Saudi Arabia is dependent the variables of the study.

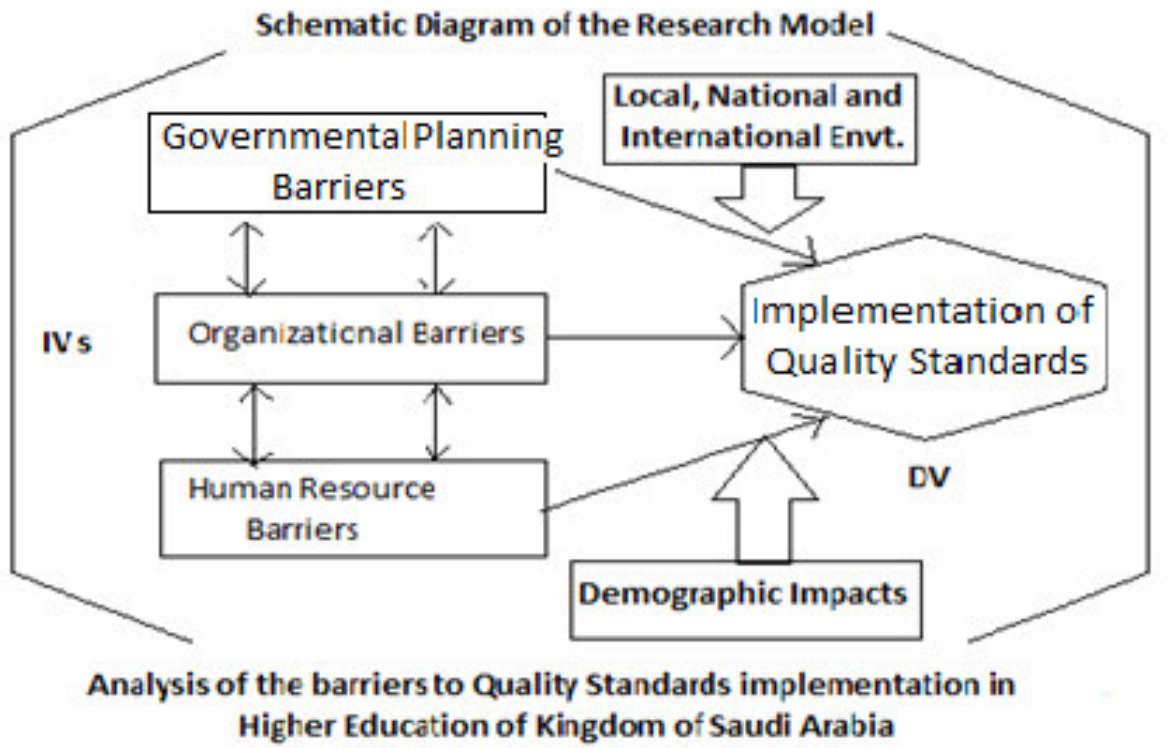

Figure-1 Research Model

\section{Discussion}

Today higher education is acknowledged as a resources investment in education. (World Bank, 2014), which have a significant role in the prosperity and development of any society. It is evident that the universities for centuries and which have positive role in the development of the potential political leaders, religious and social scholars, professionals and business men. The personalities of the society therefore, expected to serve their people 
and community, Simplicio, (2008) admits this significance and further elaborate that in the knowledge base economy, all other sectors including agriculture, industry and service cannot step on the hurdles to meet their goals unless quality education is ensured at higher education level. Prior to 2004 in Saudi Arabia there was no system of quality for higher education before establishment of the National Commission for Academic Accreditation and Assessment (NCAAA), which was initiated to operate in 2004.

During 2005 and 2006 it established and then modified the testing of the quality assurance system with focus on the standards covering institutional context, quality of learning and teaching, support for students learning, supporting the infrastructure and community contributions. In 2007 and 2008, Saudi institutions implemented the new quality assurance system and build their capacity (Eqbal et al., 2015). However, the desire of getting place at international ranking of the Saudi universities is yet to materialize as several factors impede the implementation of these quality standards in the Saudi higher education. Participation and involvement of the stake holders in quality system development, implementation have been identified as the main barriers (Onsman, 2010). Likewise, Simplicio (2008) and Raines (2007) have observed that lack of management understanding and top management support and will to implementation is weak this why still Saudi are waiting to reap the benefits of modern quality education system, Morcol (2007), Agranoff \& Yidiz (2007) and Churchman (2006) however, noted that lack of qualified and competent professional hamper the quality implementation is Saudi universities. Onsman (2010a; Onsman (2010b; Onsman (2010c) while making detail analysis found lack of involvement of the faculty, where he observed that academic staff general wish and desire to be involved in the process of quality development and implementation system, furthermore, cultural diversity, teaching skills and communication skills are the three aspects of academic environment, which need to be considered while making any decision regarding quality in higher education.

As pointed out by several research studies like, Abdullah (2010), Harvey \& Williams (2010), Mokhtar (2009) and Hillyard (2008) that appointment, promotion and awards must be based on meritocracy as according to these studies the quality of higher education is thus dependent upon the quality of the teachers. Stephen et al. (2008) and Powell (2008) asserts that lack of internationalization and contextualization, in the designing the quality standard programs for teaching, research and the programs besides the implementation of the standards, which might pose significant barriers, the researcher might have top focus. This lack of coordination and cooperation might be due to varying perceptions, miscommunication etc. however, it is argued by several researchers that to effectively put into place the quality standards in higher education institutions, there is dire need to strengthen the bod of relationship, confidence and trust between and among the higher education and national quality accreditation commission.

\section{Conclusions}

The demand of quality in higher education is unswervingly associated to the quality of teachers, students inter alia the infrastructure of the educational institutions. The competency, experience, and command on the subject of the teachers besides curricula and the standards of student intake have been considered as the significant contributing factors in the deteriorating or otherwise elevation of the quality of higher education. The study in hand highlighted some of the key factors that impede quality augmentation. The in- depth analysis of the Saudi education systems and quality standards in some of the Saudi universities indicated that there is lack of uniformity in implementation of the quality standards among different universities. Though an appropriate yardstick exist to assess the quality of the universities, however, it has been observed that there are some deviations and violations that become barriers to effective implementation of quality standards in these universities. It has been identified that the universities in Saudi Arabia are passing through the transition period. This is why the Saudi higher education and universities are moving slowly with humble pace towards improvement in the quality, where need of the hour is to implement the national and international quality control standards at earliest.

Succinctly, in the light of the findings of this study, it is concluded that an uneven quality policy may be executed in the universities. Furthermore, the properly qualified faculty may be guaranteed in these universities besides training of all members including Saudi and non-Saudi faculty may be planned. It was further, found the research activities are in the offing, whereas, it needs more attention of the authorities thus, must be placed on top priority agenda of the universities. The governmental, organizational dimensions might be streamlined to support implementation of quality standards in higher education. Participation of the teachers and faculty may also need to be ensured as they are the key stakeholders and can play key role in successful implementation of the quality standards in the universities. Moreover, effective coordination and cooperation is a pre-conditions for implementation of quality standards between and among the higher education and national quality accreditation commission.

\section{References}

1. Abdullah, S. (2010). NCAAA's patience running thin with universities. Arab News, March 02, 2010.

2. Agranoff, R., \& Yidiz, M. (2007). Decision making in public management networks. In G. Morcol (Ed.) 
Handbook of Decision Making (pp. 319-345). London: Taylor \& Francis.

3. Ascher. (1997). Principles for transnational educational courses. GATE Newsletter 2 pp. 6-7.

4. Beso, A., Bollaert, L., Curvale, B., \& Sursock, A. (Eds.). (2008). Implementing and using quality assurance: Strategy and practice. A selection of papers from the 2nd European Quality Assurance Forum. Brussels: European University Association.

5. Chande, S. U. (2006). Performance Indicators of an Institute of Higher Education. Proceeding of 1 st International Conference on Assessing Quality in Higher Education (2006). Institute of Quality \& Technology Management University of Punjab, Lahore. p.14

6. Dobbins, M., \& Knill, C. (2009). Hochschulpolitik in Mittel- und Osteuropa: Konvergenz zu einem gemeinsamen Modell? Konstanz: University of Konstanz, Department of Politics and Management, Chair of Comparative Public Policy and Administration.

7. Durlak, J. A., \& DuPre, E. P. (2008). Implementation matters: A Review of research on the influence of implementation on program outcomes and the factors affecting implementation. American Journal of Community Psychology, 41(3-4), 327-350. doi: 10.1007/s10464-008-9165-0.

8. European Association for Quality Assurance in Higher Education. (2009). Standards and guidelines for quality assurance in the European Higher Education Area, (3rd Ed.). Helsinki: European Association for Quality Assurance in Higher Education.

9. Gorga, A. (2011). Les jeux de la qualité: Impacts sur les politiques éducatives et la vie académique en Suisse et en Roumanie. Louvain-la-Neuve (BE): Academia Bruylant.

10. Harvey, L., \& Williams, J. (2010). Fifteen year of quality in higher education. Quality in Higher Education, 16(1), 3-36.

11. Heather Eggins Ed. (2013). Drivers and barriers to achieving quality in higher education. Life Long Learning Program, Sense Publishers, Rotterdam/Boston/Taipei, the Netherlands.

12. Higher Education Commission of Pakistan. (2010). Quality assurance cell. http:// www.hec.gov.pk, January $07,2010$.

13. Hillyard, M. (2008). Arab education: the front line on the war on terror. Strategic Insights. http:llwww.nps.edu/Academics/centers/ccc/publications/OnlineJournal/2008/Jul/hillyardJul08.pdf

14. James, P. Gee. (1992). Discourse analysis, In: LeCompte, M. et al. (2001). The handbook of qualitative research in education ((Eds). chapter 6), San Diego, Academic Press, USA.

15. Joshi, S.K. (2014). Quality management in hospitals. 2nd Ed. Jaypee Brother, India, pp.3-19.

16. Lundin, M. (2007). Explaining cooperation: How resource interdependence, goal congruence, and trust affect joint actions in policy implementation. Journal of Public Administration Research and Theory, 17(4), 651672 .

17. Max, V. Manen (1990). Hermeneutical Analysis: Researching lived experience, New York, State University of New York Press, USA.

18. McCarthy, D. L. (1997). Investment for development and social change. McGraw Hill. New York

19. Mokhtar, H. (2009). Universities face disqualification over academic standards. Arab News, October 27.

20. Moosa, K. (2003). Quality assurance in education: An overview. Paper presented at National Conference on Quality Assurance in Education. Pakistan Institute of Quality Control. Lahore

21. Morcol, G. (2007). Decision making: An overview of theories, contexts, and methods. Handbook of Decision Making. Pp. 3-18.London: Taylor and Francis.

22. Olaniyan, D.E., \& Okemakinde, T. (2008). Human capital theory: Implications for educational development. European Journal of scientific Research, 24(2), 152-162.

23. Onsman, A. (2010a). Cross border teaching and the globalization of higher education: Problems of funding, curriculum quality and international accreditation. Lewiston: Edwin Mellen Press.

24. Onsman, A. (2010b). Academic development: Needs analysis. Jizan City, Saudi Arabia: Jizan University International Technical Support.

25. Onsman, A. (2010c). It is better to light a candle than to ban the darkness: Contrasting academic development practices in two Saudi Arabian universities, Paper accepted for presentation at the Australian Association for Research in Education Conference, Melbourne.

26. Powell, B. (2008). Stakeholders' perception of who influences the decision-making processes in Ontario's public postsecondary education institutions. Higher Education Research \& Development, 27(4), 385-397.

27. Raines, S. (2007). Participatory decision making: Using conflict management theories, methods and skills to overcome the rational and irrational sources of conflict, In G. Morcol (Ed.), Decision making: An overview of theories, contexts, and methods (pp. 587-606) London: Taylor \& Francis.

28. Report Ministry of Higher Education of Saudi Arabia (2012). Quality and Academic Accreditation in Higher Education Institutions. https://he.moe.gov.sa/en/Ministry/General-administration-for-Publicrelations/BooksList/book4eng.pdf..

29. Saeed, K. A. (2003). Quality in higher education and universities. Paper presented at National Conference on 
Quality Assurance in Education in Pakistan. Pakistan Institute of Quality Control Lahore

30. Simplicio, J. (2008). Shared governance: An analysis of power on the modern university campus from the perspective of an administrator. Education, 126(4), 763-768.

31. Stephens, J., Hernandez, M., Roman, M., Graham, A., \& Scholz, R. (2008). Higher education as a change agent for sustainability in different cultures and contexts. International Journal of sustainability in Higher Education, 9(3), 317-338.

32. UNDP. (2002). Human development report 2002. Oxford University Press, New York.

33. UNESCO. (1996). Policy Paper for Change and Development in Higher Education. US Department of Education (2002) US Strategic Educational Plan 2002-2007, USA

34. Westerheijden et al. (2010). The first decade of working on the European higher education area: The Bologna Process independent assessment - Volume 1 detailed assessment report. s.l. [Brussels]: European Commission, Directorate-General for Education and Culture.

35. World Bank (2014). Report on Higher Education: The Lesson of Experience, Islamabad World Bank. (2000). Report on Higher Education in the Developing Countries. 